https://doi.org/10.15407/ujpe64.1.3

A. ZAVILOPULO, O. SHPENIK

Institute of Electron Physics, Nat. Acad. of Sci. of Ukraine

(21, Universytets'ka Str., Uzhgorod 88017, Ukraine; e-mail: gzavil@gmail.com)

\title{
ELECTRON-IMPACT MASS \\ SPECTROMETRY OF PTCDA MOLECULES IN THE GAS PHASE
}

\begin{abstract}
The complete and dissociative ionizations of a 3,4,9,10-perylene-tetracarboxylic-dianhydride $\left(\mathrm{C}_{24} \mathrm{H}_{8} \mathrm{O}_{6}, \mathrm{PTCDA}\right)$ molecule in the gas phase have been studied, by using electron-impact mass spectrometry in an energy interval of 5-90 eV. The molecule is found to decay into the following fragment ions: the perylene core $\mathrm{C}_{20} \mathrm{H}_{8}^{+}$and its half $\mathrm{C}_{10} \mathrm{H}_{4}^{+}$, as well as $\mathrm{CO}^{+}, \mathrm{CO}_{2}^{+}$, and $\mathrm{O}^{+}$ions. The energy dependences of the cross-sections of the complete ionization of a PTCDA molecule and its fragment ions are analyzed. The energy of the complete ionization of a PTCDA molecule and the energies, at which its fragments appear, are determined. The temperature dependences of the formation of the most intensive fragment ions are measured, by using 80-eV electrons in a temperature interval of 320-500 K.

Ke ywords: ionization, electron impact, fragment ions, energy of appearance.
\end{abstract}

\section{Introduction}

Organic substances (electrically active molecules) are widely used in modern knowledge-intensive technologies, including devices with the application of molecular electronics [1]. The functioning of the latter is based on the electron transport through molecules. Various elementary interaction processes between molecules and electrons with different energies take place at that [2]. The interaction features depend on both the electron energy magnitude and the molecular structure.

Despite that organic molecules are widely applied in molecular electronics, radiation chemistry, biology, and medicine, the available information concerning their interactions with electrons is still scarce. This circumstance stimulates the experimental and theoretical studies of elastic and inelastic interaction processes between electrons and complex molecules. In particular, this concerns the generation of positive

(c) A. ZAVILOPULO, O. SHPENIK, 2019 and negative ions, as well as the fragmentation of molecules under the action of electrons. The fragmentation of molecules due to their interaction with electrons gives rise to the appearance of radical ions. The latter can quench luminescence, which results in the degradation of molecular electronics devices.

Synthesis of new compounds on the basis of electrically active organic molecules makes it possible to produce luminescent crystals [3]. Another interesting application domain of those molecules is the synthesis of oligonucleotides, which effectively radiate within a wavelength interval from 401 to $485 \mathrm{~nm}$. Using them for DNA labeling allows novel methods for diagnosing the diseases at the cellular level to be developed $[4,5]$. Furthermore, owing to their unique properties, electrically active organic molecules are engaged in the artificial photosynthesis, by using them to form molecular structures that reproduce the key functions of natural photosynthetic membranes. In other words, they play the role of "antennas" that absorb light quanta in the blue-green spectral interval $[6,7]$.

ISSN 2071-0194. Ukr. J. Phys. 2019. Vol. 64, No. 1 


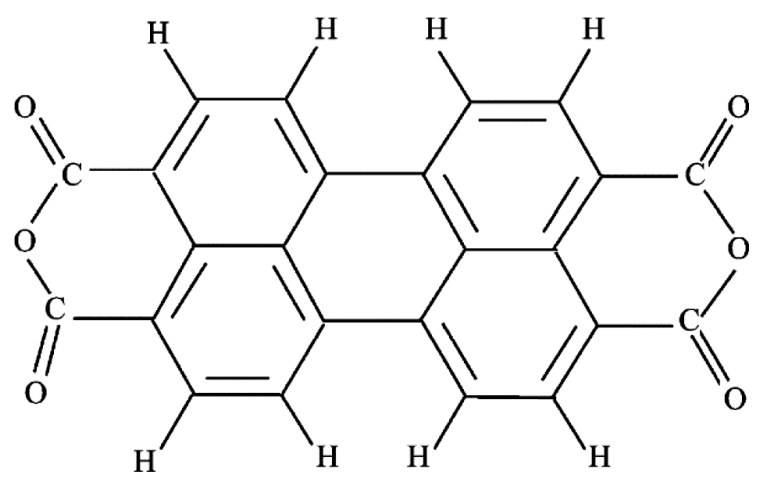

Fig. 1. Structure of a PTCDA molecule

From the aforesaid, a conclusion can be drawn that the research of mass spectra of electrically active organic molecules at various energies of ionizing electrons, as well as the determination of effective cross-sections of their direct and dissociative ionization, is a challenging task. Information on fragmentation processes, ionization energies, and thermodynamic parameters are absent or limited for most electrically active molecules. For example, the wellknown NIST database [8] contains the mass spectrum of a 3,4,9,10-perylene-tetracarboxylic-dianhydride $\left(\mathrm{C}_{24} \mathrm{H}_{8} \mathrm{O}_{6}\right.$, PTCDA $)$ molecule within the mass number interval of 26-400 Da. This is a result of certain experimental difficulties at studies of the ionization of electrically active molecules, which is confirmed by a limited number of publications on this topic, despite a considerable interest in those molecules from the developers of molecular electronics devices.

In our previous works $[9,10]$, we reported the results of our researches concerning the electron-impact ionization, both single and dissociative, of 1,4-bis $(2,5$ phenyloxazolyl)benzene (POPOP) and 9,10-bis(phenylethynyl)anthracene (BPEA) molecules in the gas phase. In this paper, for the first time, the results of mass spectrometric studies of the PTCDA molecule in an interval of $0-400 \mathrm{Da}$ are presented together with the experimental energy dependences of the effective cross-section of the single ionization of this molecule in a wide range of bombarding electron energies and molecular evaporation temperatures. A standard Sigma-Aldrich specimen (product No. 77350) was examined.

\section{Experimental Part}

As was already emphasized above, the study of complex organic molecules is a very interesting problem, because, owing to their unique optical and electronic properties, they are promising objects for organic electronics. Due to the ability of those molecules to form thin layers with the crystalline structure on various surfaces, they are most often used as organic films in photovoltaic energy converters and light emitting devices. It should be noted that, in the majority of published papers devoted to a PTCDA molecule, experiments were carried out, by using the methods of photoelectron, electron [11-13], and Xray spectroscopies [14]. The electron states of negative ions formed at the interaction of electrons with PTCDA molecules were also thoroughly studied [15]. The research of electron ionization with the yield of positive ions strongly extends our knowledge about the electron structure of a PTCDA molecule, as well as the regularities and peculiarities in the interaction of low-energy electrons with this molecule.

The complex structure of a PTCDA molecule is shown in Fig. 1. It consists of a perylene core (five benzene rings). Two anhydride groups are attached to the opposite sides of the core. Each group contains three oxygen atoms. The PTCDA molecules have a moderate chemical reactivity and form well-ordered films on various substrates, which look like a "brickwork" [12].

The experiments were performed on an installation equipped with a monopole mass spectrometer MX 7304A [10, 16] with the mass resolution $\Delta M=$ $=1$ Da. A beam of PTCDA molecules generated with the help of an effusive-type source was directed into the ionization chamber of a mass spectrometer. The concentration of molecules in the region of their interaction with electrons was about $10^{10}-10^{11} \mathrm{~cm}^{-3}$. The molecules were ionized by $5-90-\mathrm{eV}$ electrons emitted from a tungsten cathode operating in the current stabilization mode within an interval of $0.05-$ $0.5 \mathrm{~mA}$. The electron energy spread did not exceed $\Delta E=250 \mathrm{meV}$. The mass scale was calibrated with respect to the isotopes of $\mathrm{Ar}$ and Xe atoms, and the electron energy scale by the initial section in the $\mathrm{N}_{2}$ molecule ionization function.

The experiment was carried out in two stages. The mass spectrum was measured firstly in an interval of 0-400 Da; then the energy dependences of the crosssections of dissociative ionization of fragment ions were determined. A particular attention was paid to the study of the ionization threshold dependences. 
The mass spectra of a PTCDA molecule were measured at the following fixed energies of ionizing electrons: $E_{i}=10,20,30,40,50,70,80$, and $90 \mathrm{eV}$.

\section{Experimental Results and Their Discussion}

The majority of experimental and theoretical works devoted to a PTCDA molecule deal with films of this substance adsorbed on various surfaces. Note that the photon-excited mass spectra [11] contain no peaks with $\mathrm{m} / \mathrm{z}=392$ corresponding to the total mass of a PTCDA molecule, which testifies to a predominant role of the non-thermal photofragmentation mechanism. Under the electron ionization of a PTCDA molecule [13], the obtained mass spectrum, besides the main peak at $m / z=392$, also contains intense peaks corresponding to molecular cations with the masses $m / z=248,276,320$, and 348. Those peaks emerge owing to the fragmentation of a PTCDA molecule, and the intensity of the peak corresponding to the ion of the entire examined molecule is maximum.

In the mass spectrum of negative ions [15], the peaks of a $[\mathrm{PTCDA}]^{-}$molecular ion $(\mathrm{m} / \mathrm{z}=392)$ and fragment anions with the mass numbers $m / z=$ $=348,336$, and 320 were also observed. Those ions appear as a result of the removal of carbonyl groups and carbon dioxide from the molecular cation, which leads to the appearance of the following fragments: $\left.\left[\mathrm{PTCDA}-\mathrm{CO}_{2}\right]^{-}, \mathrm{PTCDA}_{-2}(\mathrm{CO})\right]^{-}$, and [PTCDA$\left.\mathrm{CO}-\mathrm{CO}_{2}\right]^{-}$. In other words, the PTCDA molecule effectively captures a slow electron $(0-10 \mathrm{eV})$ to form a negative ion. The removal of an electron from the initial molecule and the transformation of the latter into a positive ion take place at higher electron energies $E>10 \mathrm{eV}$.

When electrons collide with PTCDA molecules, there are several alternative scenarios for the generation of positively charged ions. Figure 2 illustrates a possible fragmentation scheme of a PTCDA molecule at its interaction with electrons. As one can see, the most probable way of the fragmentation consists in the removal of lateral $\mathrm{CO}$ and $\mathrm{CO}_{2}$ molecules, oxygen atom, and benzene ring. A similar picture was also observed at the photo-ionization of a PTCDA molecule [11].

\subsection{Mass spectra}

Figure 3 demonstrates one of the mass spectra of a PTCDA molecule, which was measured in a mass in-

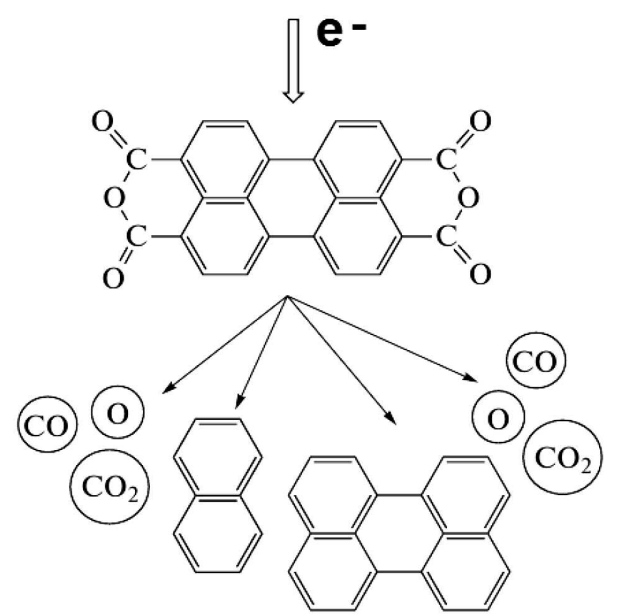

Fig. 2. Schematic diagram of the fragmentation of a PTCDA molecule after its interaction with electrons

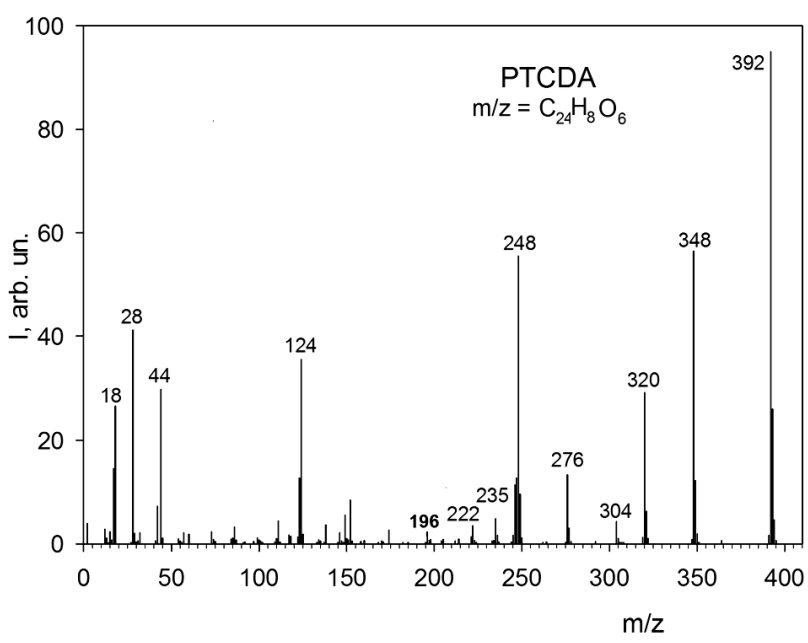

Fig. 3. Mass spectrum of a PTCDA molecule $\left(U_{i}=80 \mathrm{eV}\right.$, $T=490 \mathrm{~K})$. The bold number $m / z=196$ corresponds to the doubly charged ion $\mathrm{C}_{24} \mathrm{H}_{8} \mathrm{O}_{6}^{2+}$

terval of 0-400 Da, at a molecular source temperature of $490 \mathrm{~K}$, and the energy of ionizing electrons $E=80 \mathrm{eV}$. In an interval of $0-20 \mathrm{Da}$, there are mass peaks corresponding to the positive ions of hydrogen, oxygen, and water. The emergence of the peak corresponding to water molecules can be explained by the presence of water molecules in the polycrystalline PTCDA matrix, so that water is released when the PTCDA molecules are evaporated. The signal corresponding to the water molecule mass drastically increases with the molecular source temperature. The presence of the peaks corresponding to $\mathrm{CO}^{+}$and $\mathrm{CO}_{2}^{+}$ 
ions in the mass spectrum can be considered as a result of the fragmentation of molecules of unstable dicarboxylic group $\mathrm{C}_{2} \mathrm{O}_{3}$ at their interaction with electrons $[5,11]$. This assumption is confirmed by a similar energy distribution of those particles over the translational degrees of freedom [11].

When analyzing the mass spectrum in Fig. 3, one may also notice that the most intense peaks correspond to ions of water $\left(\mathrm{H}_{2} \mathrm{O}^{+}\right)$, atomic oxygen $\left(\mathrm{O}^{+}\right)$, carbon oxide $\left(\mathrm{CO}^{+}\right)$, and carbon dioxide $\left(\mathrm{CO}_{2}^{+}\right)$. A somewhat lower intensity of $\mathrm{CO}_{2}^{+}$peaks in comparison with $\mathrm{CO}^{+}$ones stems from the dissociation of the $\mathrm{CO}_{2}$ fragment and the formation of atomic oxygen. In a similar way, we can explain the formation of the peaks of $\mathrm{H}_{2}^{+}$molecules and atomic oxygen $\mathrm{O}^{+}$ in the mass spectrum due to the dissociation of water and carbon dioxide molecules. This assumption is confirmed by a similar picture observed in the mass spectrum of negative ions [15]. The fact that the intensity of the signal corresponding to the $\mathrm{CO}^{+}$ion exceeds the $\mathrm{CO}_{2}^{+}$signal can also be explained by a partial decay of $\mathrm{CO}_{2}$ molecules into $\mathrm{CO}$ and oxygen during the decomposition of carbonyl terminals. This also testifies that the interaction of electrons with PTCDA molecules leads to the removal and decay of carbonyl groups. Thus, in our opinion, the appearance of atomic oxygen ion $(m / z=16)$ is a result of combined processes: the dissociation of $\mathrm{CO}_{2}$ molecules $\left(\mathrm{CO}_{2}=\mathrm{CO}+\mathrm{O}\right)$ and the charge localization at the oxygen atom (see Fig. 2 ) at the $\beta$-cleavage of molecular ions $[17,18]$.

In the large-mass interval, there are a few intense peaks of molecular fragment ions, whpse apperance can be explained by the following reaction chain ${ }^{1}$ :

$$
\begin{aligned}
& \mathrm{e}^{-}+\mathrm{C}_{24} \mathrm{H}_{8} \mathrm{O}_{6} \rightarrow \\
& \rightarrow \mathrm{C}_{23} \mathrm{H}_{8} \mathrm{O}_{4}^{+}(m / z=348)+\mathrm{CO}_{2} \rightarrow \\
& \rightarrow \mathrm{C}_{22} \mathrm{H}_{8} \mathrm{O}_{3}^{+}(m / z=320)+2 \mathrm{CO}+\mathrm{O} \rightarrow \\
& \rightarrow \mathrm{C}_{22} \mathrm{H}_{8} \mathrm{O}_{2}^{+}(m / z=304)+2 \mathrm{CO}+2 \mathrm{O} \rightarrow \\
& \rightarrow \mathrm{C}_{21} \mathrm{H}_{8} \mathrm{O}^{+}(m / z=276)+\mathrm{CO}_{2}+2 \mathrm{CO}+\mathrm{O} \rightarrow \\
& \rightarrow \mathrm{C}_{20} \mathrm{H}_{8}^{+}(m / z=248)+\mathrm{CO}_{2}+3 \mathrm{CO}+\mathrm{O} \rightarrow \\
& \rightarrow \mathrm{C}_{19} \mathrm{H}_{7}^{+}(m / z=235)+\mathrm{CO}_{2}+3 \mathrm{CO}+\mathrm{O}+\mathrm{CH} \rightarrow \\
& \rightarrow \mathrm{C}_{18} \mathrm{H}_{6}^{+}(m / z=222)+\mathrm{CO}_{2}+3 \mathrm{CO}+\mathrm{O}+\mathrm{C}_{2} \mathrm{H}_{2} .
\end{aligned}
$$

\footnotetext{
1 This is one of possible variants from a variety of ionfragmentation processes.
}

The appearance of a $\mathrm{C}_{20} \mathrm{H}_{8}^{+}$ion $(m / z=248)$ peak in the mass spectrum corresponds to the perylene core of a $\mathrm{C}_{20} \mathrm{H}_{8}$ molecule, and the appearance of a peak at $m / z=124$ to its half, the $\mathrm{C}_{10} \mathrm{H}_{4}^{+}$ion, emerging as a result of the dissociation of $\mathrm{C}_{20} \mathrm{H}_{8}^{+}$into two identical parts. The presence of peaks corresponding to $\mathrm{C}_{18} \mathrm{H}_{7}^{+}(m / z=222)$ and $\mathrm{C}_{17} \mathrm{H}_{6}^{+}(m / z=235)$ ions in the mass spectrum (Fig. 3) can be explained by the interaction of electrons with the perylene core. Those ions should be classified as fragments of a PTCDA molecule, because their intensity depends on the evaporation temperature. This conclusion is confirmed by the data of work [13], in which those ions were also observed in the mass spectrum. This fact can be explained as follows: the relaxation energy leads to the break of internal molecular bonds both in the perylene core itself and between the perylene core and terminal carboxyl groups.

We also observed a peak corresponding to the doubly charged ion $\mathrm{C}_{24} \mathrm{H}_{8} \mathrm{O}_{6}^{2+}(m / z=196)$ emerging in the reaction

$\mathrm{e}^{-}+\mathrm{C}_{24} \mathrm{H}_{8} \mathrm{O}_{6} \rightarrow \mathrm{C}_{24} \mathrm{H}_{8} \mathrm{O}_{6}^{2+}+3 \mathrm{e}^{-}$.

Surely, the intensity of this peak was low. In the general case, the probability of the emergence of multiply charged ions in the case where electrons and photons collide with electrically active molecules is low (the method of electrospray ionization is an exception). However, the generation of doubly charged ions is inherent in molecules of aromatic compounds [17]. In other words, the appearance of the doubly charged ion of a PTCDA molecule in the mass spectrum confirms this reaction.

Hence, the presented fragmentation scheme (1) of a PTCDA molecule into positive ions (this is only one of the possible variants) testifies to the strong decomposition of this molecule at its interaction with electrons. This is also confirmed by a rather high fragmentation degree of the molecule. In order to analyze the fragmentation process, one can additionally pay attention to theoretical calculations of binding energies $[19,20]$. The lowest binding energy in the PTCDA molecule $(3.6 \mathrm{eV})$ corresponds to the single $\mathrm{C}-\mathrm{C}$ bond between the perylene core and the carboxyl group. The energy of the single $\mathrm{C}-\mathrm{O}$ bond has approximately the same value, the energy of the $\mathrm{C}-$ $\mathrm{C}$ bond in the aromatic ring (see Fig. 2) amounts to $5.3 \mathrm{eV}$, and the double bond $\mathrm{C}=\mathrm{O}$ has an energy of 
$7.8 \mathrm{eV}$ [19]. Two naphthalene fragments are linked by two $\mathrm{C}-\mathrm{C}$ bonds with an energy of $4.2 \mathrm{eV}$, which is less than the corresponding value in the aromatic ring. A comparison of the indicated energies for the internal molecular bonds in the PTCDA molecule testifies to a predominant role of the non-thermal fragmentation mechanism at evaporation temperatures below $500 \mathrm{~K}$.

\subsection{Energy dependences}

The tuning of a mass spectrometer to detect a definite mass made it possible to measure the relative formation cross-sections of the most intense fragment ions that arise in the course of dissociative ionization of a PTCDA molecule within an energy interval from the ionization threshold to $90 \mathrm{eV}$. The total relative ionization cross-section was obtained by measuring the total current created by ions at the collector [22].

In Fig. 4, the energy dependence of the total relative ionization cross-section (the ionization function) measured for a PTCDA molecule is depicted. The threshold section of this curve (the inset in Fig. 4) was used to determine the molecule ionization energy. By analyzing the ionization function of a PTCDA molecule, one can see that the curve slowly increases at its initial section from the threshold to $40 \mathrm{eV}$; then, it drastically increases when the energy grows to $70 \mathrm{eV}$; afterward, a smooth decrease takes place. The threshold section contains several features in the form of small peaks, whose energy positions coincide with the energies, at which the fragment ions $\mathrm{O}^{+}, \mathrm{CO}^{+}$, and $\mathrm{CO}_{2}^{+}$appear [22].

Figure 5 illustrates the threshold sections in the energy dependences obtained for the formation of fragment ions of the oxygen atom $\mathrm{O}^{+}$and the molecules $\mathrm{CO}^{+}, \mathrm{CO}_{2}^{+}$, and $\mathrm{H}_{2} \mathrm{O}^{+}$. As one can see, all exhibited curves are characterized by a slow increase from the ionization threshold, which is followed by a rather rapid growth. At certain energies of bombarding electrons, a number of additional cusp-like features appear in the threshold section of the ionization function.

The peculiarities in the energy dependence describing the formation of fragment ions can be explained by the switching-on of new reaction channels, as the electron energy increases. For example, it was shown in work [15] that, when PTCDA molecules interact with low-energy electrons in the gas phase, negative molecular and fragment ions arise in accordance with

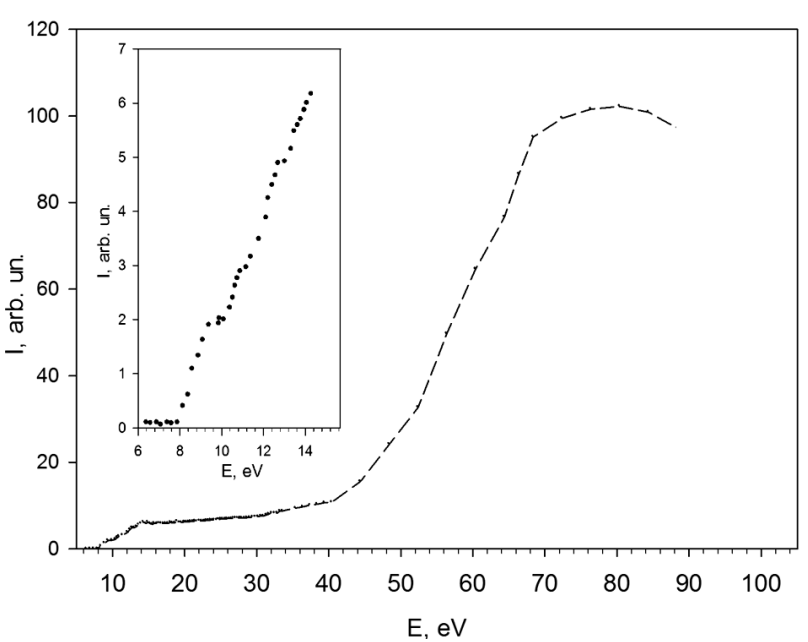

Fig. 4. Total relative ionization cross-section of a PTCDA molecule. The threshold section of the ionization function is shown in the inset
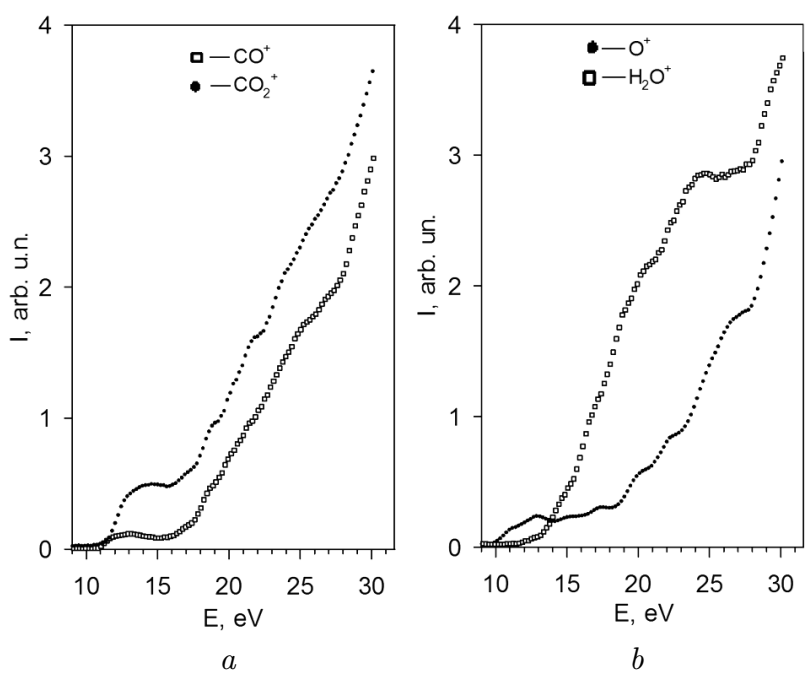

Fig. 5. Threshold sections in the energy dependences of the formation of fragments ions of carbon oxide $(a)$ and dioxide oxygen and water $(b)$

the resonance mechanism. Furthermore, one cannot exclude that the peculiarities in those energy dependences may probably be associated with the type and energies of molecular orbitals. In particular, a group of broad maxima corresponding to vacant $\sigma$-orbitals may emerge at incident electron energies of 8.1, 10.6, and $14.4 \mathrm{eV}$.

Surely, in order to substantiate a mechanism giving rise to the appearance of those features more thoroughly, a detailed theoretical consideration is 
Ionization energies $E_{\mathrm{ip}}$ and the energies $\boldsymbol{E}_{\mathrm{ap}}$, at which fragment ions of a PTCDA molecule appear

\begin{tabular}{|c|c|c|c|c|c|c|c|}
\hline \multirow{3}{*}{ Ion } & \multirow{3}{*}{$m / z$} & \multicolumn{5}{|c|}{$E_{\mathrm{ip}}, \mathrm{eV}$} & \multirow{3}{*}{$\begin{array}{c}E_{\mathrm{ap}}, \mathrm{eV} \\
\begin{array}{c}\text { Experiment } \\
\text { (our data) }\end{array}\end{array}$} \\
\hline & & \multicolumn{2}{|c|}{ Experiment } & \multicolumn{3}{|c|}{ Calculation } & \\
\hline & & Our data & {$[21]$} & [19] & {$[20]$} & [18] & \\
\hline $\mathrm{C}_{24} \mathrm{O}_{6} \mathrm{H}_{8}^{+}$ & 392 & $8.11 \pm 0.25$ & 8.2 & 8.00 & 8.14 & 7.68 & - \\
\hline $\mathrm{O}^{+}$ & 16 & - & - & - & - & - & $10.61 \pm 0.25$ \\
\hline $\mathrm{H}_{2} \mathrm{O}^{+}$ & 18 & - & - & - & - & - & $12.72 \pm 0.25$ \\
\hline $\mathrm{CO}^{+}$ & 28 & - & - & - & - & - & $11.54 \pm 0.25$ \\
\hline $\mathrm{CO}_{2}^{+}$ & 44 & - & - & - & - & - & $12.11 \pm 0.25$ \\
\hline $\mathrm{C}_{20} \mathrm{H}_{8}^{+}$ & 248 & - & - & - & - & - & $17.40 \pm 0.25$ \\
\hline $\mathrm{C}_{10} \mathrm{H}_{4}^{+}$ & 124 & - & - & - & - & - & $21.50 \pm 0.25$ \\
\hline
\end{tabular}

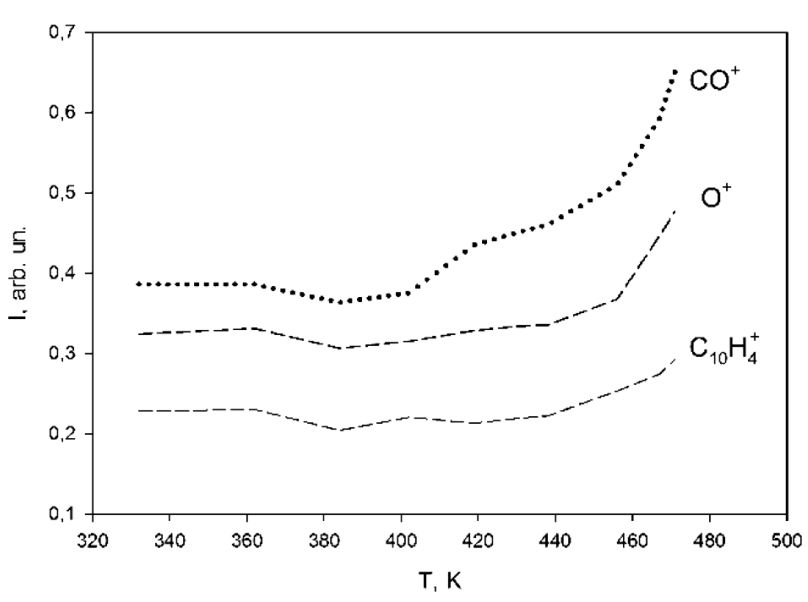

Fig. 6. Temperature dependences of the formation of fragment ions $\mathrm{O}^{+}, \mathrm{CO}^{+}$, and $\mathrm{C}_{10} \mathrm{H}_{4}^{+}$of a PTCDA molecule $\left(U_{i}=80 \mathrm{eV}\right)$

required with regard for the binding energies in a PTCDA molecule. In so doing, it should be borne in mind that the lowest energy of $3.6 \mathrm{eV}$ corresponds to a single $\mathrm{C}-\mathrm{C}$ bond between the perylene core and the terminal carboxyl group. In our opinion, the most promising in this aspect are calculations of the electron structure of a PTCDA molecule. In view of the complicated character of this structure, various theoretical approaches based on the density functional theory (DFT) with the LDA, GGA, and B3LYP correlation functionals, as well as the GW method, are used for the calculation of the valence electron structure of PTCDA. The results of calculations are compared with experimental data [20]. For instance, it was shown in work [20] that the difference between the energies of LUMO-HOMO states in a PTCDA molecule calculated according to the difference between the electron affinity and ionization energies agrees well with experimental data [23].

As was emphasized above, in works $[9,10]$, the energies, at which the fragment ions appear, and the ionization energy of a PTCDA molecule were determined, by using the least-squares method on the basis of experimental data for the threshold sections in the energy dependences of the fragment ion formation and the total relative ionization cross-section of a PTCDA molecule. The results obtained for some intense fragment ions (Fig. 3) are quoted in Table 1 . In the literature $[8,21]$, there are no experimental and theoretical results [18-20] concerning the energies $E_{\text {ap }}$, at which the fragment ions of a PTCDA molecule appear. A comparative analysis of the data presented in the table for the ionization energy $E_{\text {ap }}$ demonstrates a satisfactory coincidence of our results with experimental data [21] and theoretical calculation results [18-20].

\subsection{Temperature dependences}

It is known $[11,14]$ that, in the case of electrically active molecules, including PTCDA, the temperature of the transition into the gas phase substantially affects the dynamics of the evaporation process and a change of the molecular structure [24]. As a result, the binding energies in a PTCDA molecule decrease, and, accordingly, the efficiency of its decay changes. Hence, 
the ratios between the fragment yield (or formation) intensities at the interaction of the molecule with lowenergy electrons can vary with the temperature.

To elucidate the temperature effect on the processes of PTCDA molecule dissociation, we measured the temperature dependences of the formation of the most intensive fragment ions $\mathrm{O}^{+}, \mathrm{CO}^{+}$, and $\mathrm{C}_{10} \mathrm{H}_{4}^{+}$ at an electron energy of $80 \mathrm{eV}$ in a temperature interval of $320-500 \mathrm{~K}$. The corresponding results are shown in Fig. 6. As one can see, in this temperature interval, the depicted dependences have a similar behavior in general. The yields of ions differ only by different growing rates with the temperature for light $\left(\mathrm{O}^{+}\right.$and $\left.\mathrm{CO}^{+}\right)$and heavy $\left(\mathrm{C}_{10} \mathrm{H}_{4}^{+}\right)$ions. In particular, the yields of $\mathrm{O}^{+}$and $\mathrm{CO}^{+}$ions sharply increase with the temperature, by starting from $460 \mathrm{~K}$. For a $\mathrm{C}_{10} \mathrm{H}_{4}^{+}$ion, the yield growth also takes place above $T=440 \mathrm{~K}$, but it is considerably slower. Since the sublimation of PTCDA molecules begins at a temperature higher than $630 \mathrm{~K}$ [11], the thermally induced destruction of intramolecular bonds is appreciable under our conditions. Therefore, the specimen temperature affects the formation intensity of separate components [14].

\section{Conclusions}

In this work, it was shown that the method of electron-impact mass spectrometry is promising for the experimental and theoretical studies of the processes of elastic and inelastic interaction between electrons with complex molecules. The method makes it possible to obtain information about the processes of fragmentation, dissociation, and ionization of such molecules and determine the energy and thermodynamic characteristics of the latter.

The mass spectra and the energy dependences of the formation of positive ions of a 3,4,9,10-perylenetetracarboxylic-dianhydride $\left(\mathrm{C}_{24} \mathrm{H}_{8} \mathrm{O}_{6}, \quad\right.$ PTCDA $)$ molecule in the gas phase by low-energy electrons are experimentally studied. On the basis of the obtained mass spectra, it is found that the main channels of the PTCDA molecule decay due to the electron impact are the processes of fragment ion formation. These are the light singly charged ions $\mathrm{CO}^{+}, \mathrm{CO}_{2}^{+}$, and $\mathrm{O}^{+}$; the heavy signgly charged ions $\mathrm{C}_{10} \mathrm{H}_{4}^{+}, \mathrm{C}_{20} \mathrm{H}_{8}^{+}, \mathrm{C}_{18} \mathrm{H}_{7}^{+}, \mathrm{C}_{20} \mathrm{H}_{8}^{+}, \mathrm{C}_{22} \mathrm{H}_{8} \mathrm{O}_{2}^{+}$, $\mathrm{C}_{22} \mathrm{H}_{8} \mathrm{O}_{3}^{+}$, and $\mathrm{C}_{23} \mathrm{H}_{8} \mathrm{O}_{4}^{+}$, and the doubly charge ion $\mathrm{C}_{24} \mathrm{H}_{8} \mathrm{O}_{6}^{2+}$.
The complete (integral) ionization of a PTCDA molecule and the most intense fragment ions in an energy interval of 6-90 eV are studied. By analyzing the threshold section in the curve obtained for the total relative ionization cross-section with the use of the least-squares method, the ionization energy of a PTCDA molecule is determined, which agrees well with the results of theoretical calculations. The energies corresponding to the appearance of intense fragment ions are determined for the first time. The temperature dependences of the formation of the most intense fragment ions at an electron energy of $80 \mathrm{eV}$ are measured in a temperature interval of $320-500 \mathrm{~K}$. It is found that the formation of light ions $\left(\mathrm{O}^{+}\right.$and $\left.\mathrm{CO}^{+}\right)$ drastically increases at temperatures above $460 \mathrm{~K}$. At the same time, the formation of heavy $\mathrm{C}_{10} \mathrm{H}_{4}^{+}$ions increases very slowly above $T=440 \mathrm{~K}$.

The authors express their gratitude to E.Yu. Remeta and R.S. Gedeon for their help and valuable remarks on the paper.

1. M. Di Ventra, S. Evoy, R. Heflin. Introduction to Nanoscale Science and Technology (Kluwer Academic Publ., 2004).

2. A.V. Kukhto. Electroluminescence of thin films of organic compounds (A review). Zh. Prikl. Spektrosk. 70, 151 (2003) (in Russian).

3. R. Gimenez, M. Pinol, J.L. Serrano. Luminescent liquid crystals derived from 9,10-bis(phenylethynyl)anthracene. Chem. Mater. 16, 1377 (2004).

4. N.N. Dioubankova, A.D. Malakhov, Z.O. Shenkarev, V.A. Korshun. Oligonucleotides containing new fluorescent 1-phenylethynylpyrene and 9,10-bis(phenylethynyl)anthracene uridine- 2 '-carbamates: Synthesis and properties. Tetrahedron 60, 4617 (2004).

5. A.D. Malakhov, M.V. Skorobogatyi, I.A. Prokhorenko, S.V. Gontarev, D.T. Kozhich, D.A. Stetsenko, I.A. Stepanova, Z.O. Shenkarev, Y.A. Berlin, V.A. Korshun. 1(phenylethynyl)pyrene and 9,10 bis(phenylethynyl)anthracene, useful fluorescent dyes for DNA labeling: Excimer formation and energy transfer. Eur. J. Org. Chem. 6, 1298 (2004).

6. A.L. Moore, D. Gust, T.A. Moore. Bio-inspired constructs for sustainable energy production and use. Actual. Chimique No. 308039, 50 (2007).

7. K. Kilså, A.N. Macpherson, T. Gillbro, J. Mårtensson, Bo Albinsson. Control of electron transfer in supramolecular systems. Spectrochim. Acta A 571, 2213 (2001).

8. G. Mallard, P.J. Linstrom. NIST Standard Reference Database, Vol. 69 (2000) [http://www.webbook.nist.gov].

9. L. Romanova, A. Zavilopulo, A. Kukhta, I. Kukhta. Dissociative ionization of 1,4-bis(2,5-phenyloxazolyl) benzene. Int. J. Mass Spectrom. 279, 10 (2009). 
10. A.V. Kukhta, I.N. Kukhta, A.N. Zavilopulo, A.S. Agafonova, O.B. Shpenik. Ionization of 4,4'-bis(phenylethynyl)anthracene by electron impact. Eur. J. Mass Spectrom. 15, 563 (2009).

11. A.G. Ramonova, I.V. Tvauri, S.A. Khubezhov. Photoinduced decomposition of PTCDA molecules and desorption of their fragments from the films formed on the $\operatorname{GaAs}(110)$ surface. Russ. J. Phys. Chem. A 89, 1944 (2015).

12. N. Dori, M. Menon, L. Kilian. Valence electronic structure of gas-phase 3,4,9,10-perylene tetracarboxylic acid dianhydride: Experiment and theory. Phys. Rev. B 73, 195208 (2006).

13. J. Wüsten, Th. Ertl, S. Lach, Ch. Ziegler. Post deposition purification of PTCDA thin films. Appl. Surf. Sci. 252, 104 (2005).

14. S.W. Cho, D. Newby, jr., A. DeMasi, K.E. Smith, L.F.J. Piper, T.S. Jones. Determination of the individual atomic site contribution to the electronic structure of 3,4,9,10-perylene-tetracarboxylic-dianhydride (PTCDA). J. Chem. Phys. 139, 184711 (2013).

15. S.A. Pshenichnyuk, A.V. Kukhto, I.N. Kukhto, A.S. Komolov. Spectroscopic states of negative PTCDA ions and their relation to the vacant state density maxima in the conduction band. Zh. Tekhn. Fiz. 81, No. 6, 8 (2011) (in Russian).

16. A.N. Zavilopulo, E.A. Mironets, A.S. Agafonova. An upgraded ion source for a mass spectrometer. Instrum. Experim. Techn. 55, 65 (2012).

17. A.T. Lebedev. Mass Spectrometry in Organic Chemistry (BINOM, 2003) (in Russian).

18. E.V. Tikhonov, Yu.A. Uspenskii, D.R. Khokhlov. Features of the electron structure and photoemission spectra of organic molecular semiconductors: Metal-phthalocyanine molecules and PTCDA. Pis'ma Zh. Eksp. Teor. Fiz. 98 17 (2013) (in Russian).

19. S. Sharifzadeh, A Biller, L Kronik, J.B. Neaton. Quasiparticle and optical spectroscopy of the organic semiconductors pentacene and PTCDA from first principles. Phys. Rev. B 85, 125307 (2012).

20. X. Blase, C. Attaccalite, V. Olevano. First-principles GW calculations for fullerenes, porphyrins, phtalocyanine, and other molecules of interest for organic photovoltaic applications. Phys. Rev. B 83, 115103 (2011).

21. N. Marom, X. Ren, J.E. Moussa, J.R. Chelikowsky, L. Kronik. Electronic structure of copper phthalocyanine from $\mathrm{G}_{0} \mathrm{~W}_{0}$ calculations. Phys. Rev. B 84, 195143 (2011).

22. O.B. Shpenyk, O.V. Pylypchynets, A.M Zavilopulo. Fragmentation of PTCDA molecule by electron impact. Dopov. Nats. Akad. Nauk Ukr. No. 2, 43 (2018).

23. M. Wewer, F. Stienkemeier. Molecular versus excitonic transitions in PTCDA dimers and oligomers studied by helium nanodroplet isolation spectroscopy. Phys. Rev. B 67, 125201 (2003).

24. E.F. Lazneva, A.M. Turiev, S.A. Komolov. Laser-stimulated fragmentation and desorption from the organic film surface: 1-derivatives of perylene. Pis'ma Zh. Tekhn. Fiz. 35, 88 (2009) (in Russian).

Received 10.05.18.

Translated from Ukrainian by O.I. Voitenko

\section{А.М. Завілопуло, О.Б. Шпеник}

\section{МАС-СПЕКТРОМЕТРІЯ МОЛЕКУЛИ}

\section{РТСDА ЕЛЕКТРОННИМ УДАРОМ В ГАЗОВІЙ ФАЗІ}

$\mathrm{P}$ е $з$ ю м е

Методом спектрометрії електронного удару в діапазоні енергії бомбардуючих електронів 5-90 еВ досліджено повну та дисоціативну іонізацію молекули 3,4,9,10-діангідриду тетракарбоксильної кислоти перилена $\mathrm{C}_{24} \mathrm{H}_{8} \mathrm{O}_{6}$ (PTCDA) у газовій фазі. Встановлено, що під дією електронів молекула розпадається на такі фрагментарні іони: периленове ядро $\mathrm{C}_{20} \mathrm{H}_{8}+$, його половина $\mathrm{C}_{10} \mathrm{H}_{4}^{+}$, а також іони $\mathrm{CO}^{+}, \mathrm{CO}_{2}{ }^{+}$ та $\mathrm{O}^{+}$. Досліджено функції повної (інтегральної) іонізації молекули PTCDA та деяких фрагментарних іонів, а методом найменших квадратів за пороговою ділянкою кривих відносного перерізу іонізації визначені енергії іонізації молекули РTCDA та енергї появи іонів фрагментів. Вивчені температурні залежності формування найбільш інтенсивних іонів фрагментів в інтервалі температур 320-500 К при енергії електронів $80 \mathrm{eB}$. 